\title{
Primary Mediastinal HER2-positive Apocrine Carcinoma in Mature Teratoma Treated With Anti-HER2 Therapy and Chemoradiation
}

\author{
KEIJI SUGIYAMA ${ }^{1}$, AKARI IWAKOSHI $^{2,3}$, MARIKO SATOH ${ }^{1}$, KAZUHIRO SHIRAISHI $^{1}$, KAZUKI NOZAWA $^{1}$, \\ YOSHIHITO KOGURE ${ }^{1,4}$, CHIYOE KITAGAWA ${ }^{1,4}$, SUZUKO MORITANI ${ }^{2,5}$, ERIKO KATOH ${ }^{6}$ and HIDEO SAKA ${ }^{1,4}$ \\ Departments of ${ }^{1}$ Medical Oncology, ${ }^{2}$ Pathology, ${ }^{4}$ Respirology Medicine, and \\ ${ }^{6}$ Radiation Oncology, Nagoya Medical Center, Nagoya, Japan; \\ ${ }^{3}$ Department of Surgical Pathology, Aichi Medical University Hospital, Nagakute, Japan, \\ ${ }^{5}$ Division of Molecular and Diagnostic Pathology, Shiga University of Medical Science, Otsu, Japan
}

\begin{abstract}
Background: There are no established guidelines for the management of apocrine carcinomas of the breast; they are treated as a non-specific type of breast cancer. Case Report: We report on the case of a 40-year-old man who developed primary mediastinal apocrine carcinoma overexpressing human epidermal growth factor-2 (HER2). The patient initially underwent complete resection of a mediastinal mature teratoma with a focal apocrine carcinoma component. Two years after surgery, relapse was detected in multiple mediastinal lymph nodes. He received induction chemotherapy including docetaxel, trastuzumab, and pertuzumab; consolidative concurrent chemoradiation was added after six cycles. A complete response was confirmed using computed tomography following this multimodal therapy. After chemoradiation, adjuvant trastuzumab and pertuzumab were administered for 1 year and the patient has since had no evidence of progressive disease. Conclusion: A multi-modal regimen that includes an anti-HER2 agent appears to be a promising treatment for patients with HER2positive extramammary apocrine carcinoma.
\end{abstract}

Primary mediastinal tumours encompass a variety of histological types including thymoma/thymic cancer, germ cell tumours, cystic disease, neurogenic tumours, lymphoma,

This article is freely accessible online.

Correspondence to: Keiji Sugiyama, Department of Medical Oncology, Nagoya Medical Center, 4-1-1 Sannomaru, Naka-ku, Nagoya, Aichi 460-0001, Japan. Tel: +81 529511111, Fax: +81 529713334, e-mail: keiji.sugi@gmail.com

Key Words: Apocrine carcinoma, chemoradiation, mediastinal tumour, pertuzumab, trastuzumab. thyroid neoplasm, and others $(1,2)$. Mediastinal mature teratomas are a typical histological subtype of germ cell tumour that are composed of mature tissues derived from two or three germ cell layers (1); they are pluripotential tissues capable of transforming along these germinal lines. As a result, teratomas can develop into malignant non-germ cell tumours (somatictype malignancies). Mediastinal mature teratomas with somatictype malignant components are rare, but carry dismal prognoses, while mature teratomas per se have excellent prognoses after complete resection (1). A wide variety of somatic malignancies have been described, but apocrine carcinoma arising in a mediastinal mature teratoma has only been reported in the ovaries $(3,4)$. Apocrine carcinoma is a rare subtype of breast cancer (5); it accounts for $<5 \%$ of the biological phenotypes of such cancer (6). Immunohistochemical analyses found that $54 \%$ of apocrine carcinomas of the breast overexpress human epidermal growth factor-2 (HER2) protein; they are negative for sex-hormone receptor as well as for oestrogen receptor $(\mathrm{ER})$ and progesterone receptor $(\mathrm{PgR})$, but are positive for androgen receptor (AR) $(7,8)$.

There are no established guidelines for the management of apocrine carcinoma of the breast; therefore, apocrine cancer is treated as non-specific type of breast cancer (5).

We report the case of a 40-year-old man who developed primary mediastinal apocrine carcinoma overexpressing HER2.

\section{Case Report}

A 40-year-old man presented to our facility after developing dyspnoea and chest pain. Thoracic computed tomography (CT) revealed a posterior mediastinal tumour, and magnetic resonance imaging indicated the possibility of a cystic tumour with a lipid-rich component (Figure 1). The mediastinal tumour was completely resected under general anaesthesia. 
Macroscopically, the excised large uniocular cystic tumour exhibited a focally thickened wall containing keratinized material (Figure 2A and B). Microscopically, the cystic wall was predominantly composed of mature ectodermal (i.e. squamous epithelium and other adnexal structures including apocrine glands) and mesodermal (i.e. smooth muscles, nerves, and cartilage) elements (Figure 2C). On gross examination, the nodular area was composed of apocrine carcinoma with large pleomorphic nuclei and abundant eosinophilic cytoplasm (Figure 2D and E). Immunohistochemically, there was strong circumferential membranous HER2 staining in carcinoma cells (Figure 2F). The tumour was also positive for AR (Figure 2G), cytokeratin 7, and gross cystic disease fluid protein-15 (GCDFP15), but was negative for ER and PgR. The apocrine carcinoma was postulated to have arisen from pre-existing apocrine glands in the mature teratoma as a transformed malignant component. The histological diagnosis was mature teratoma with apocrine carcinoma based on the most recent histological classification of the World Health Organization (WHO) (1). The tumour was confined within the cyst, with no evidence of infiltration outside the capsule. Lymphovascular invasion was not detected on the examined tissue sections; furthermore, neither an immature teratoma nor other malignant germ cell tumour components were found. After surgery, physical examination and ${ }^{18} \mathrm{~F}$-fluorodeoxyglucose positron-emission tomography (FDG-PET)/CT were performed to detect residual tumours or new primary lesions in locations other than the mediastinum, although none were found.

Two years after surgery, the patient visited our facility again complaining of dyspnoea and chest pain. Contrast-enhanced CT and FDG-PET/CT showed adenopathy in multiple mediastinal lymph nodes with FDG accumulation (Figure 3). Endobronchial ultrasound-guided transbronchial needle aspiration was performed, whereupon the patient was diagnosed with a recurrence of apocrine carcinoma. As with the original tumour, the recurrent lesions overexpressed HER2 and were positive for cytokeratin 7, GCDFP15, and AR but negative for ER and PgR. The patient received systemic chemotherapy including docetaxel $\left(75 \mathrm{mg} / \mathrm{m}^{2}\right.$, every 3 weeks $)$, trastuzumab ( $8 \mathrm{mg} / \mathrm{kg}$ and then $6 \mathrm{mg} / \mathrm{kg}$, every 3 weeks), and pertuzumab (840 mg then $420 \mathrm{mg}$, every 3 weeks) based on the treatment strategy devised for patients with HER2-positive breast cancer (9). After completing six cycles of induction chemotherapy, partial response was achieved according to the Response Evaluation Criteria in Solid Tumours (version 1.1) (10). Documented adverse events (according to the Common Terminology Criteria for Adverse Events) (11) were neutropenia (grade 4), febrile neutropenia (grade 3), and alopecia (grade 3 ). Aside from systemic therapy, consolidative concurrent radiation (60 Gy in 30 fractions, five times per week for 6 weeks, with target delineation based on FDGPET/CT findings at the time of recurrence) with administration
A

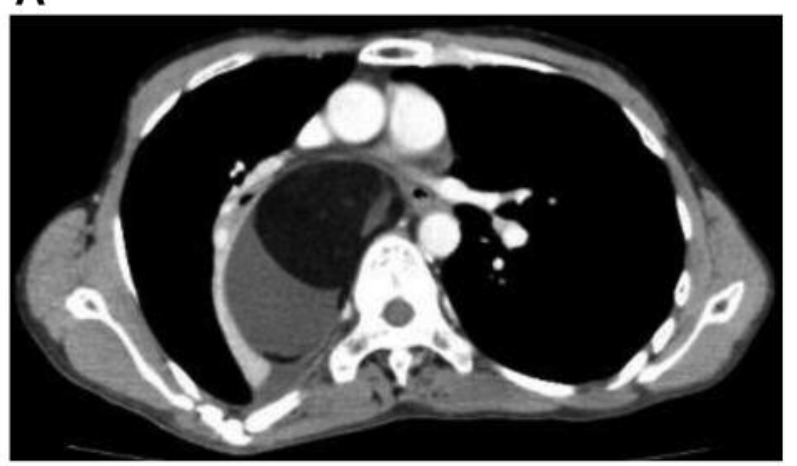

B

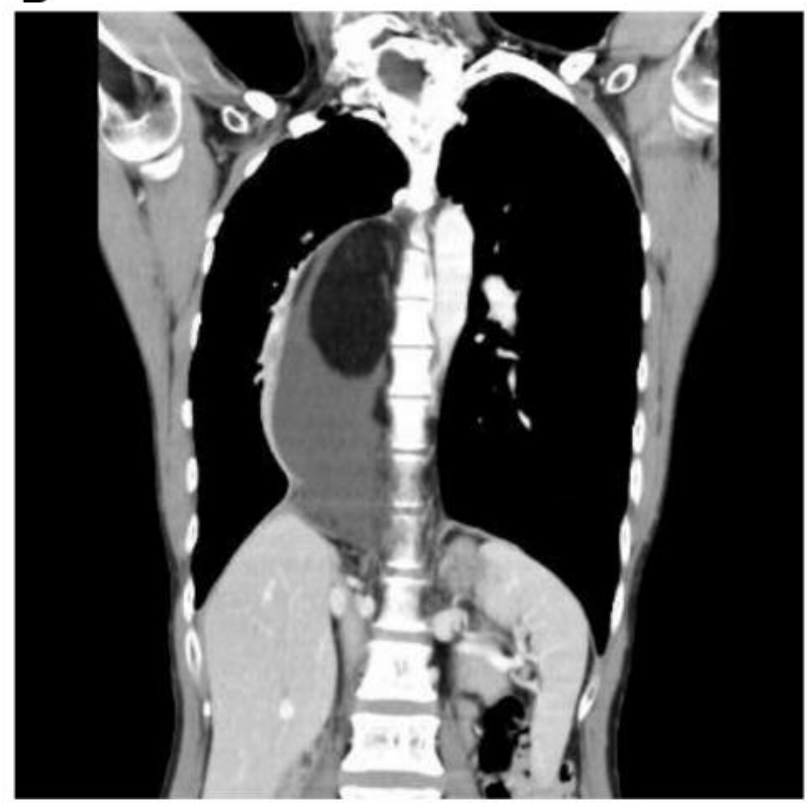

Figure 1. Contrast-enhanced computed tomographic images with the posterior mediastinal tumour in an axial (A) and sagittal slice (B) at initial diagnosis.

of weekly paclitaxel (40 mg/m $\mathrm{m}^{2}$ on days $1,8,15,22,29$, and 36) was added. During chemoradiation, the patient developed radiation-associated oesophagitis and bacterial pneumoniae (both grade 3). After chemoradiation, CT revealed that the lymph node adenopathy had disappeared (Figure 4). The patient received adjuvant anti-HER2 therapy (trastuzumab and pertuzumab) for 1 year; no evidence of disease progression was detected thereafter.

\section{Discussion}

According to most recent WHO classification, primary mediastinal apocrine carcinoma in a mature teratoma is described as a germ cell tumour with a somatic-type solid 
A

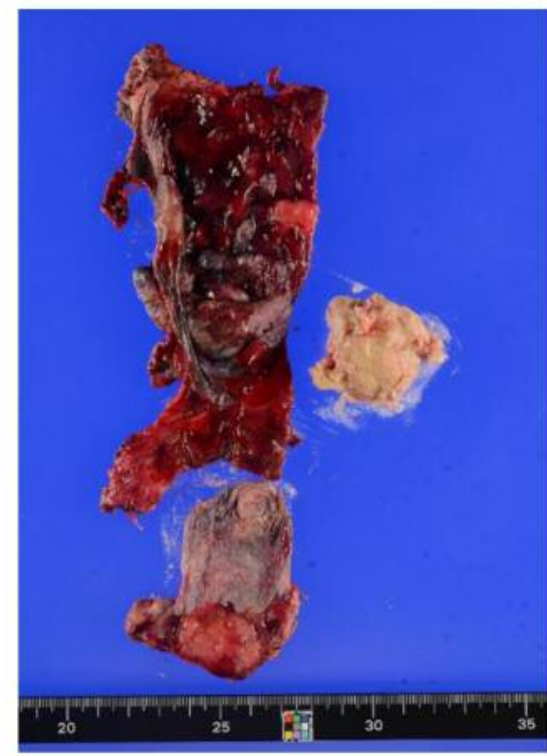

B

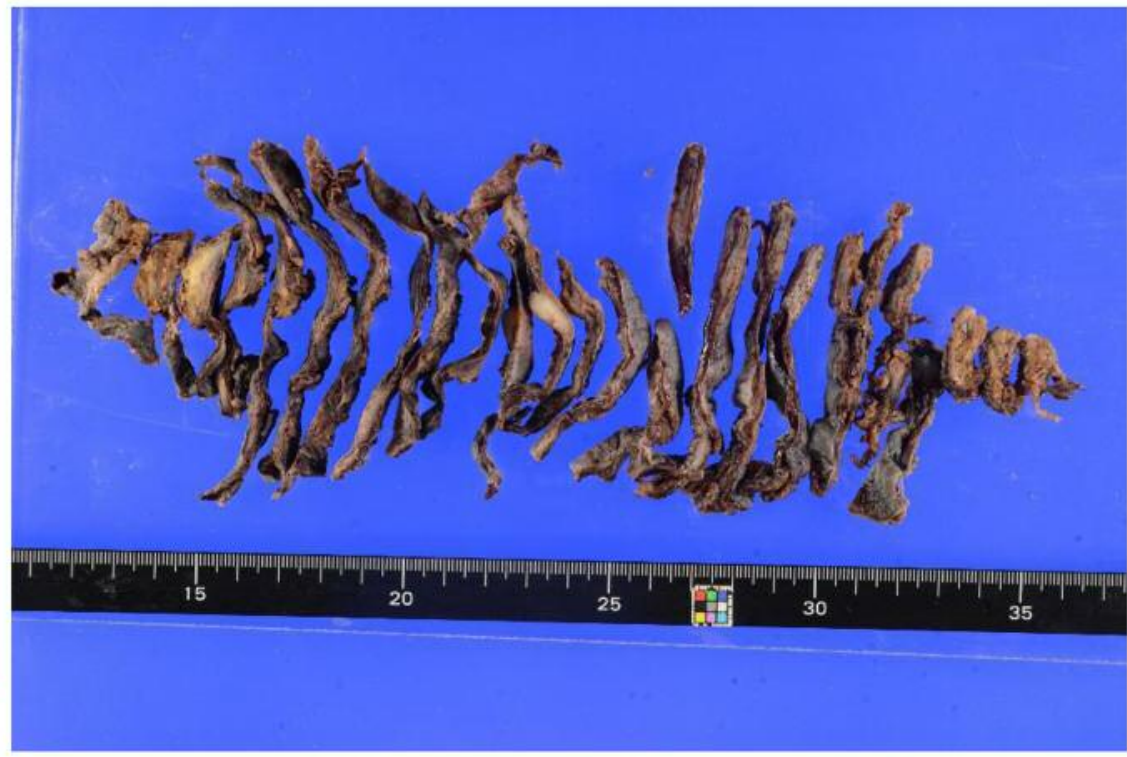

C

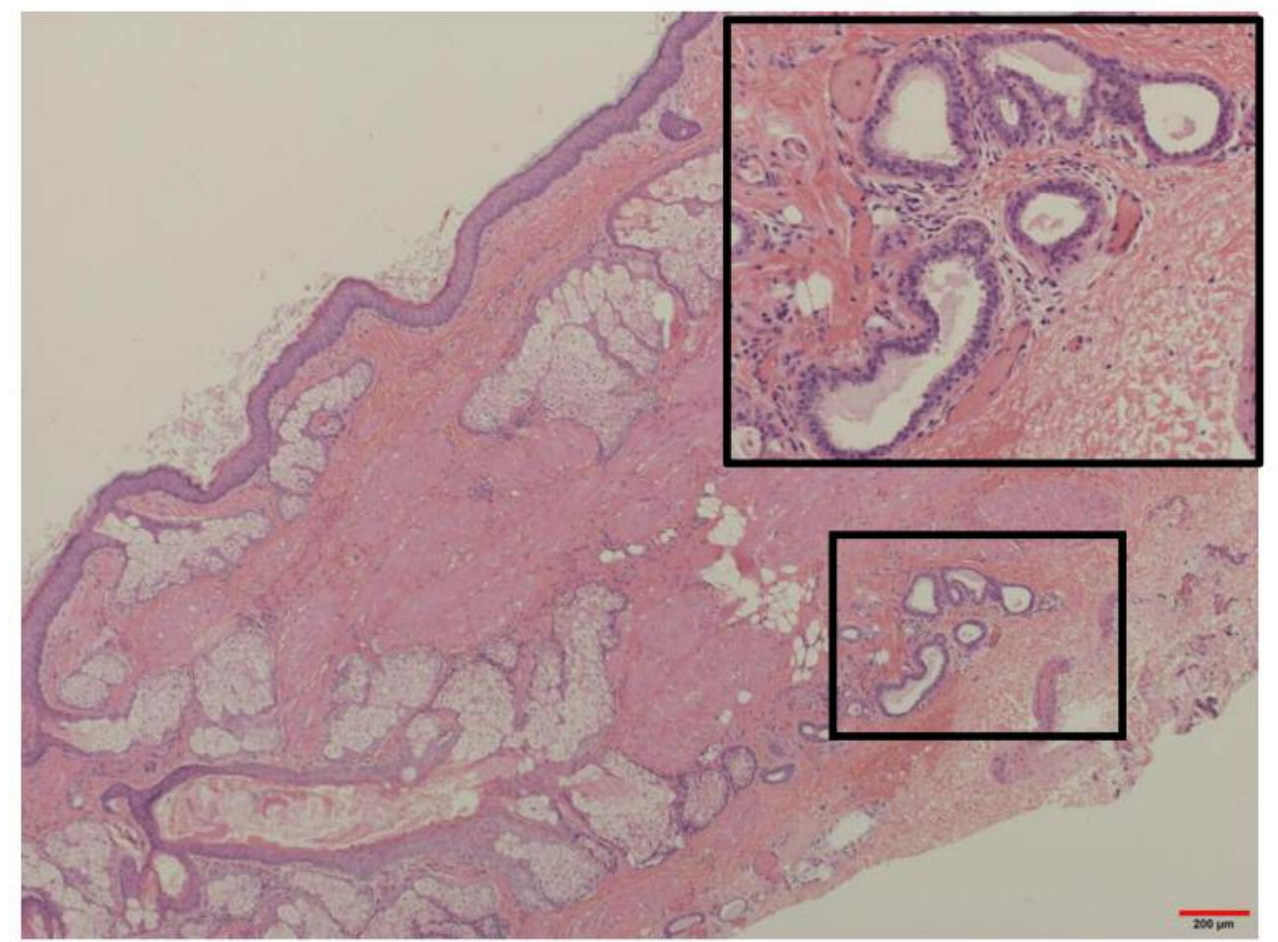

Figure 2. Continued

malignancy (12). The prognoses of patients with these tumours are poor because of their resistance to chemotherapies used for the treatment of other germ cell tumours; hence, treatment should be individualized based on the lesion's histology (13-16). Epithelial malignancies associated with germ cell tumours are mostly colonic-type adenocarcinoma (12). To date, only 21 patients with mediastinal mature teratomas that underwent malignant transformation into adenocarcinoma have been reported, five of whom had lymph node metastases (17). To the best of our knowledge, ours is the first report of the type of disease manifestation described herein, although apocrine 


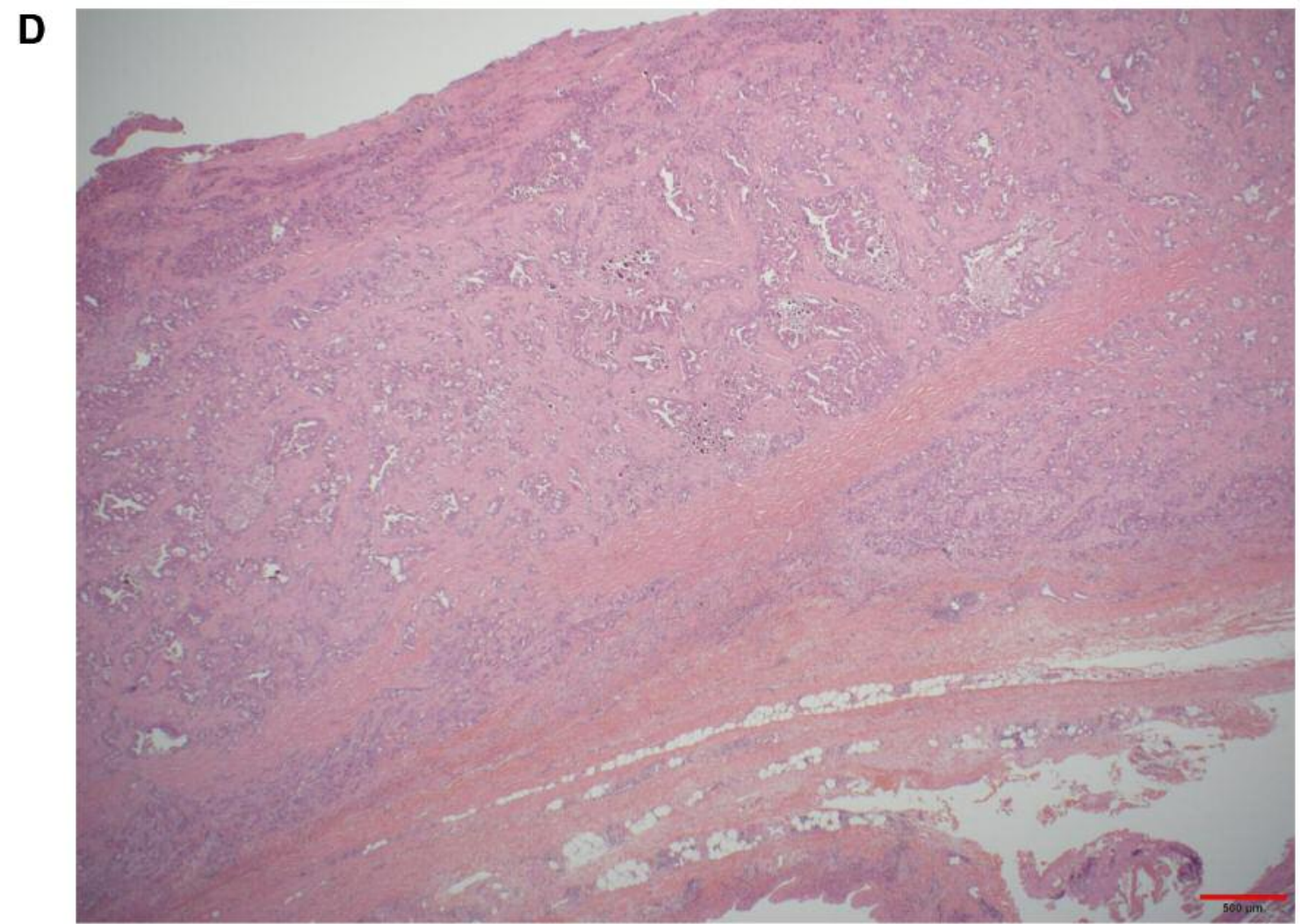

E

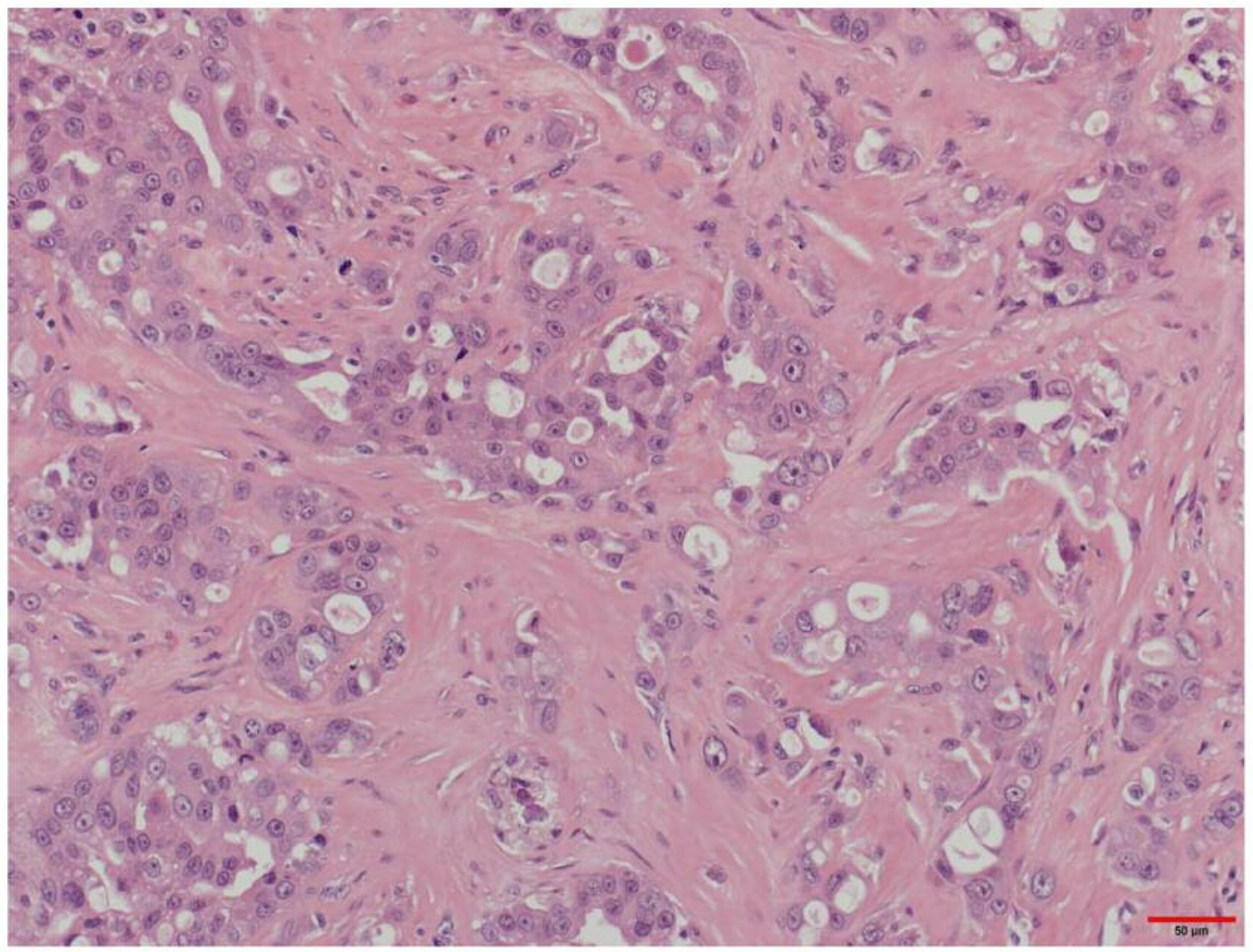

Figure 2. Continued 
$\mathbf{F}$

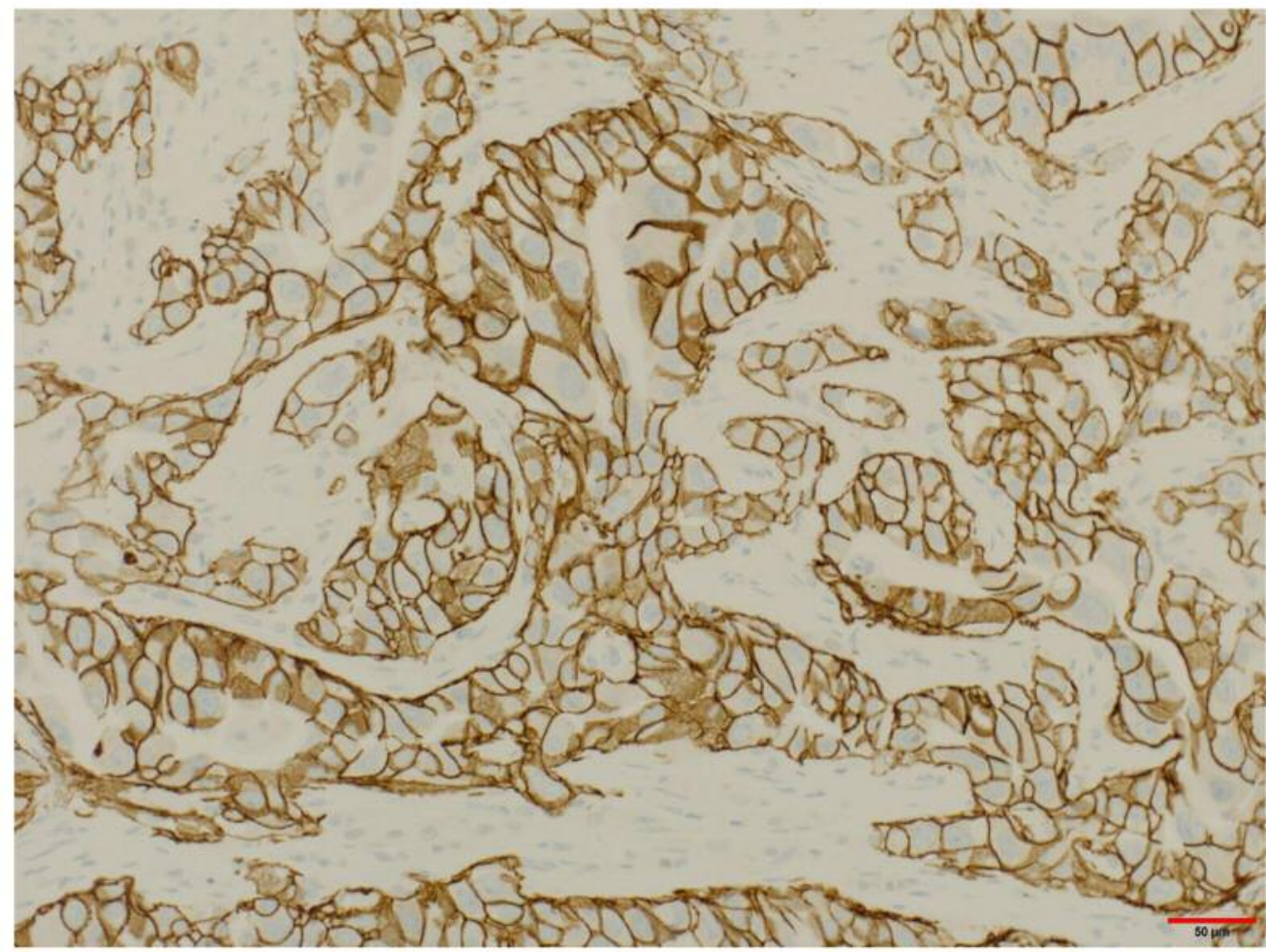

G

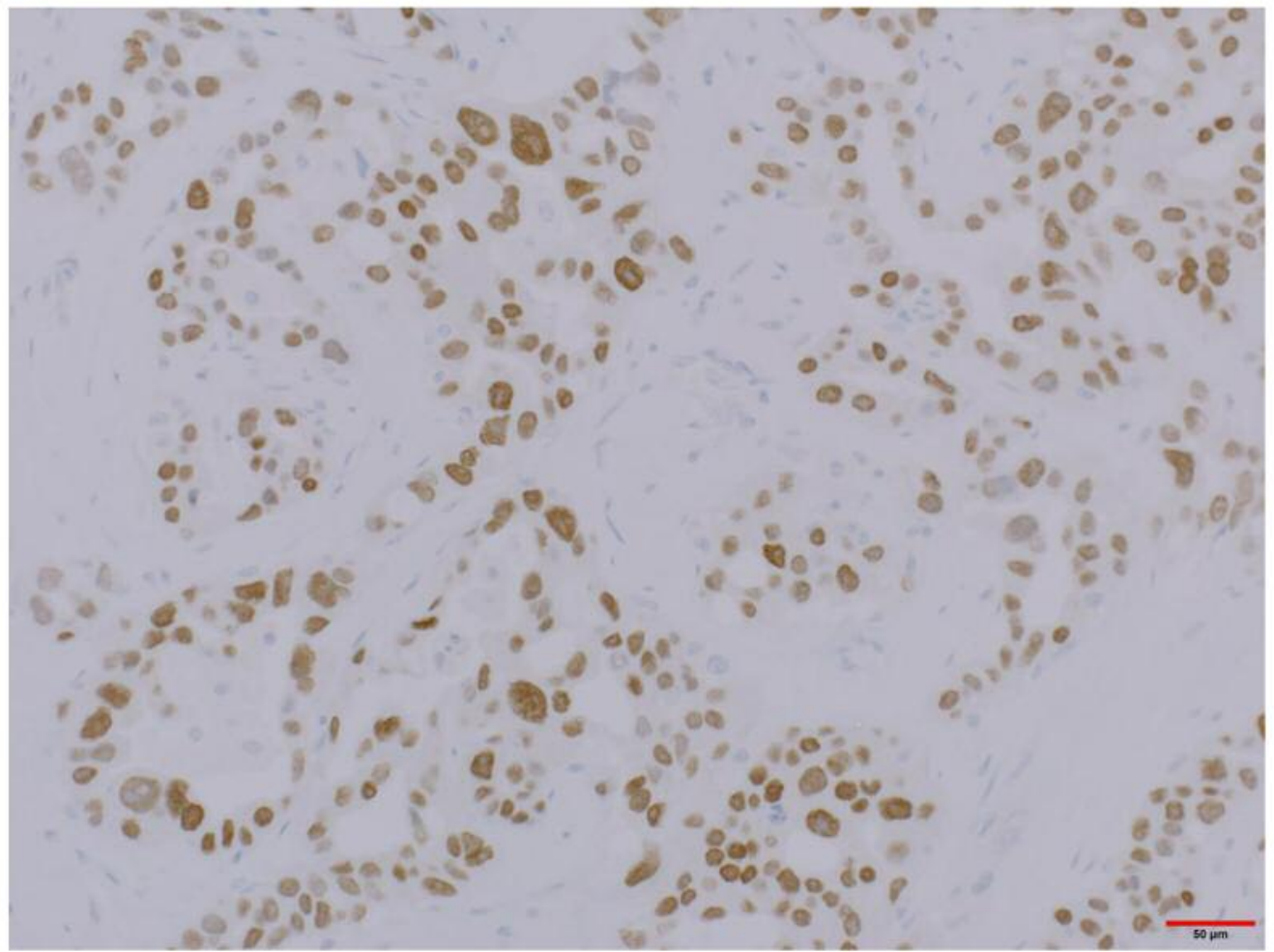

Figure 2. Macroscopic and microscopic features of the tumour. A: Gross and B: serially sectioned appearance of a uniocular cystic posterior mediastinal tumour with keratin flakes. The cystic wall was focally thickened. C: The inner surface was predominantly lined by keratinizing squamous epithelium with other adnexal structures (inset: well-differentiated apocrine glands). D: A segment of the cystic wall showing nodular thickening composed of apocrine adenocarcinoma. E: Carcinoma cells had enlarged nuclei with prominent nucleoli and abundant eosinophilic cytoplasm. Strong immunopositivity for human epidermal growth factor-2 $(F)$ and androgen receptor $(G)$ is evident. 
A

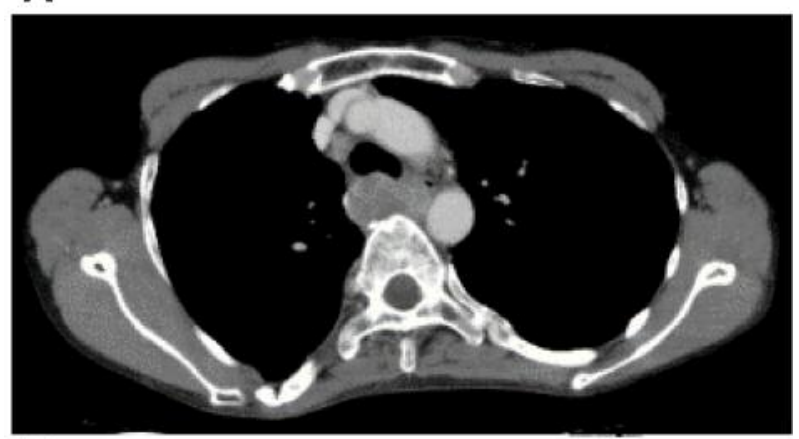

B

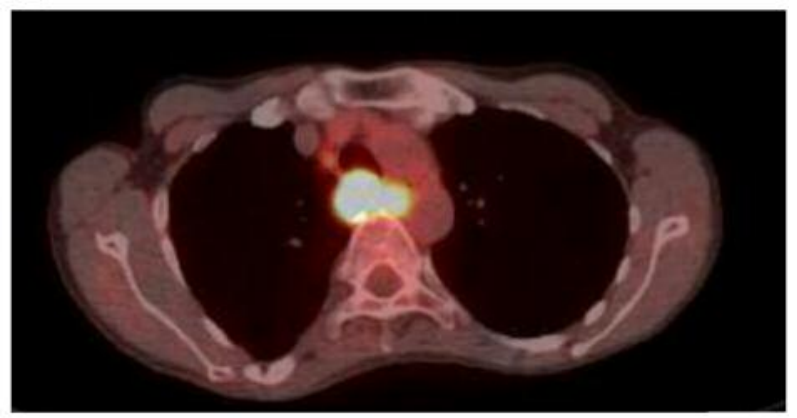

C

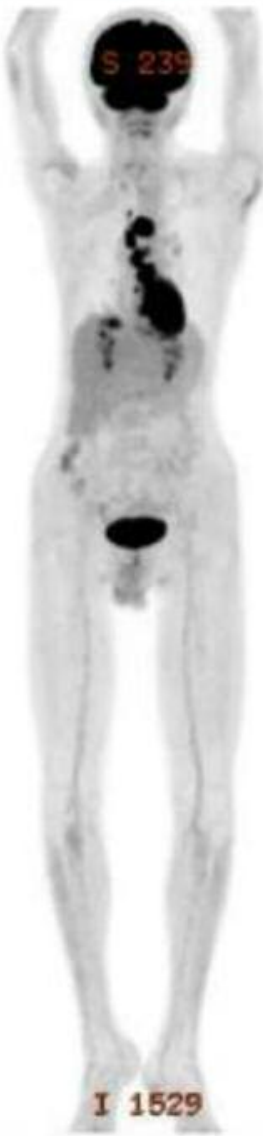

Figure 3. Images by contrast-enhanced computed tomography (A) and ${ }^{18} \mathrm{~F}$ fluorodeoxyglucose positron-emission tomography/computed tomography $(B, C)$ at recurrence.

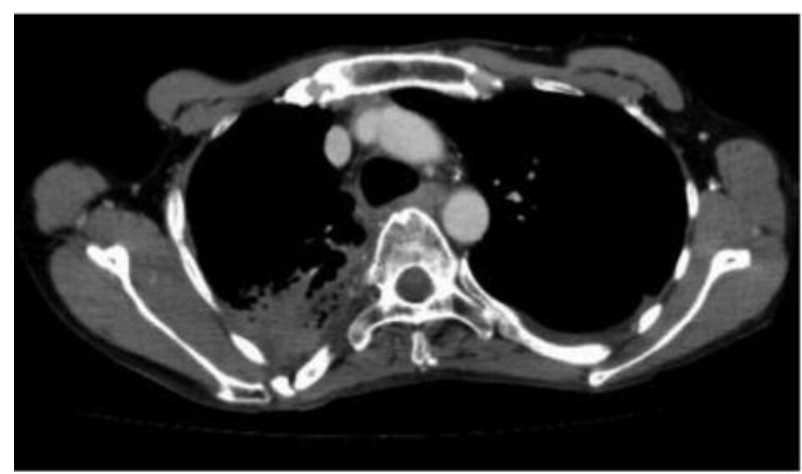

Figure 4. Contrast-enhanced computed tomographic image after the completion of induction chemotherapy and concurrent chemoradiation.

carcinoma arising from ovarian mature teratoma was previously described $(3,4)$.

Our patient's tumour presented several interesting characteristics. Firstly, the origin of the apocrine carcinoma was unique, as apocrine carcinoma generally originates in the breast or apocrine gland. Secondly, anti-HER2 therapy was used to treat our patient's mediastinal tumour based on its molecular and pathological phenotype. The current standard treatment for HER2-positive metastatic breast cancer was established by the CLEOPATRA trial, and comprises docetaxel, trastuzumab, and pertuzumab (HPD); this combination regimen produced favourable prognoses in patients with HER2-positive metastatic breast cancer, with a median overall survival of 56 months (9). HPD was also administered to patients with operable HER2-positive breast cancer; the NeoSphere trial found that this therapy achieved a pathological complete response rate of $45.8 \%$ (18). A post hoc exploratory analysis of the CLEOPATRA study outcomes revealed no significant extension of survival time beyond six cycles of treatment (19); therefore, we did not administer docetaxel after induction chemotherapy.

Since the standard adjuvant anti-HER2 therapy is 1 year of trastuzumab alone or in combination with pertuzumab, we sequentially administered adjuvant trastuzumab and pertuzumab for 1 year following induction chemotherapy. Furthermore, we administered chemoradiation therapy to treat locoregional recurrence. Some previous studies found that chemoradiation therapy for locally advanced or recurrent breast cancer was sufficiently effective $(20,21)$, with $30-60 \%$ of patients with locally advanced or recurrent breast cancer achieving a complete response; paclitaxel combined with radiation therapy was the most popular regimen. Our experience with the patient described herein ought to provide an incentive for clinicians to adopt anti-HER2-containing regimens combined with chemoradiation for local control in patients with HER2-positive extramammary apocrine carcinoma. 


\section{Conclusion}

Our patient, who had a primary mediastinal HER2-positive apocrine carcinoma in a mature teratoma, achieved a favourable clinical outcome following a multi-modal regimen that included anti-HER2 therapy. The use of anti-HER2containing regimens for HER2-positive extramammary apocrine carcinoma, thus, 0 appears to be a reasonable treatment approach.

\section{Acknowledgements}

The Authors thank Editage (www.editage.jp) for English language editing.

\section{References}

1 Azizad S, Sannananja B and Restrepo CS: Solid tumors of the mediastinum in adults. Semin Ultrasound CT MR 37: 196-211, 2016.

2 Takeda S, Miyoshi S, Akashi A, Ohta M, Minami M, Okumura M, Masaoka A and Matsuda H: Clinical spectrum of primary mediastinal tumors: A comparison of adult and pediatric populations at a single Japanese institution. J Surg Oncol 83: 24 30, 2003.

3 Yasui W, Kameda T, Harada D, Nakatani H, Hata J, Ito H and Tahara E: A case of sweat gland carcinoma arising in a mature cystic teratoma of the ovary. Gan No Rinsho 33: 875-880, 1987 (in Japanese).

4 Holmes $\mathrm{M}$ and Robb $\mathrm{T}$ : A rare case of primary apocrine adenocarcinoma arising within a mature cystic teratoma of the ovary, metastatic to a supraclavicular lymph node. Int J Gynecol Pathol 37: 344-346, 2018.

5 Cadoo KA, McArdle O, O'Shea AM, Power CP and Hennessy BT: Management of unusual histological types of breast cancer. Oncologist 17: 1135-1145, 2012.

6 O'Malley FP and Bane A: An update on apocrine lesions of the breast. Histopathology 52: 3-10, 2008.

7 Matsuo K, Fukutomi T, Hasegawa T, Akashi-Tanaka S, Nanasawa $\mathrm{T}$ and Tsuda $\mathrm{H}$ : Histological and immunohistochemical analysis of apocrine breast carcinoma. Breast Cancer 9: 43-49, 2002 .

8 Vranic S, Tawfik O, Palazzo J, Bilalovic N, Eyzaguirre E, Lee LM, Adegboyega P, Hagenkord J and Gatalica Z: EGFR and HER-2/neu expression in invasive apocrine carcinoma of the breast. Mod Pathol 23: 644-653, 2010.

9 Swain SM, Baselga J, Kim SB, Ro J, Semiglazov V, Campone M, Ciruelos E, Ferrero JM, Schneeweiss A, Heeson S, Clark E, Ross G, Benyunes MC and Cortés J; CLEOPATRA Study Group: Pertuzumab, trastuzumab, and docetaxel in HER2positive metastatic breast cancer. N Engl J Med 372: 724-734, 2015

10 Eisenhauer EA, Therasse P, Bogaerts J, Schwartz LH, Sargent D, Ford R, Dancey J, Arbuck S, Gwyther S, Mooney M, Rubinstein L, Shankar L, Dodd L, Kaplan R, Lacombe D and Verweij J: New Response Evaluation Criteria in Solid Tumours: Revised RECIST guideline (version 1.1). Eur J Cancer 45: 228247,2009
11 Cancer Therapy Evaluation Program (CTEP): Common Terminology Criteria for Adverse Events (CTCAE) v4.0. [online] Available at: http://ctep.cancer.gov/protocol Development/ electronic_applications/ctc.htm\#ct, 2010

12 Ströbel P, Chan JKC, Looijenga LHJ, Marx A, Moreira AL, Ulbright TM and Wick M: Germ cell tumours with somatic-type solid malignancy. In: WHO Classification of Tumours of the Lung, Pleura, Thymus and Heart. Fourth Edition. Travis WD, Brambilla E, Burke AP, Marx A and Nicholson AG (eds). Lyon, IARC, pp. 263-264, 2015.

13 Motzer RJ, Amsterdam A, Prieto V, Sheinfeld J, Murty VV, Mazumdar M, Bosl GJ, Chaganti RS and Reuter VE: Teratoma with malignant transformation: diverse malignant histologies arising in men with germ cell tumors. J Urol 159: 133-138, 1998.

14 Donadio AC, Motzer RJ, Bajorin DF, Kantoff PW, Sheinfeld J, Houldsworth J, Chaganti RS and Bosl GJ: Chemotherapy for teratoma with malignant transformation. J Clin Oncol 21: 42854291, 2003.

15 Faure Conter C, Fresneau B, Thebaud E, Bertrand A, Dijoud F, Rome A, Dumesnil C, Castex MP, Ghanem A and Orbach D: Two tumors in 1: What should be the therapeutic target? Pediatric germ cell tumor with somatic malignant transformation. J Pediatr Hematol Oncol 39: 388-394, 2017.

16 Speir R, Cary C, Foster RS and Masterson TA: Management of patients with metastatic teratoma with malignant somatic transformation. Curr Opin Urol 28: 469-473, 2018

17 Le Fèvre C, Vigneron C, Schuster H, Walter A, Marcellin L, Massard G,Lutz P and Noël G: Metastatic mediastinal mature teratoma with malignant transformation in a young man with an adenocarcinoma in a Klinefelter's syndrome: Case report and review of the literature. Cancer Radiother 22: 255-263, 2018

18 Gianni L, Pienkowski T, Im YH, Roman L, Tseng LM, Liu MC, Lluch A, Staroslawska E, de la Haba-Rodriguez J, Im SA, Pedrini JL, Poirier B, Morandi P, Semiglazov V, Srimuninnimit V, Bianchi G, Szado T, Ratnayake J, Ross G and Valagussa P: Efficacy and safety of neoadjuvant pertuzumab and trastuzumab in women with locally advanced, inflammatory, or early HER2positive breast cancer (NeoSphere): A randomised multicentre, open-label, phase 2 trial. Lancet Oncol 13: 25-32, 2012.

19 Miles D, Im YH, Fung A, Yoo B, Knott A, Heeson S, Beattie MS and Swain SM: Effect of docetaxel duration on clinical outcomes: Exploratory analysis of CLEOPATRA, a phase III randomized controlled trial. Ann Oncol 28: 2761-2767, 2017.

20 Karasawa K, Saito M, Hirowatari H, Izawa H, Furuya T, Ozawa $\mathrm{S}$, Ito $\mathrm{K}$, Suzuki $\mathrm{T}$ and Mitsuhashi $\mathrm{N}$ : The role of chemoradiotherapy in patients with unresectable $\mathrm{T} 4$ breast tumors. Breast Cancer 20: 254-261, 2013.

21 Shaughnessy JN, Meena RA, Dunlap NE, Jain D, Riley EC, Quillo AR, Dragun AE: Efficacy of concurrent chemoradiotherapy for patients with locally recurrent or advanced inoperable breast cancer. Clin Breast Cancer 15: 135-142, 2015.

Received December 3, 2018

Revised December 13, 2018

Accepted December 14, 2018 